\title{
A ATUAÇÁO DA SOCIEDADE DIANTE DA FALHA DE GOVERNANÇA DO ESTADO NO CASO DA CRISE HÍDRICA DE SÃO PAULO (2013-2015)
}

André Augusto Giuriatto Ferraço ${ }^{1}$

Universidade de Brasília (UnB)

Bárbara Borges Carvalho Piauilino ${ }^{2}$ Universidade de Brasília (UnB)

Marina Raísa Correia e Castro Figuerôa ${ }^{3}$ Universidade de Brasília (UnB)

Maria Vitória Soldatelli Silva Bastian ${ }^{4}$

Universidade de Brasília (UnB)

Artigo recebido em: 21/05/2020.

\section{Resumo}

Artigo aceito em: 01/10/2020.

O objetivo do artigo é analisar a atuação da sociedade diante das falhas de governança do poder público estatal em situação de crise hídrica. Para tanto, utiliza-se o estudo de caso da crise hídrica de São Paulo, entre os anos de 2013 e 2015, amparado pelo método dedutivo e a técnica de análise normativa nacional de modo dialogado com a jurisprudência, a revisão bibliográfica e os relatórios sobre o caso de São Paulo. Constatadas as principais falhas de governança do Poder Público estadual, investiga-se quais as formas de organização e atuação da sociedade para o enfrentamento de crise e, do mesmo modo, quais as principais contribuições do Direito para o tratamento da crise hídrica. Como resultados da investigação, destacam-se a necessidade de aperfeiçoamento do modelo participativo de gestão da água, tendo

1 Doutorando e mestre em Direito pela UnB, na Linha Internacionalizaçâo, Trabalho e Sustentabilidade, com ênfase em Sustentabilidade, Meio Ambiente e Direitos Humanos. Bacharel em Direito pela Faculdade de Direito de Vitória (FDV). Professor voluntário na Faculdade de Direito da UnB. Membro do Grupo de Estudos em Direito, Recursos Naturais e Sustentabilidade, da Universidade de Brasília (GERN/UnB), atuando nas pesquisas de mudanças climáticas e recursos hídricos. ORCID: http://orcid.org/0000-0003-0229-1190. E-mail: andreaugusto.gf@gmail.com 2 Graduanda em Direito na UnB. Membro do Centro de Pesquisa Percursos, Narrativas, Fragmentos: História do Direito e Constitucionalismo (UnB) e do Centro Acadêmico de Direito (UnB). Estagiária no Superior Tribunal de Justiça. E-mail: barbaraborgescp@gmail.com

3 Graduanda em Direito na UnB. Membro do Grupo de Pesquisa e Estudos de Processo Civil (UnB). Estagiária no escritório Maneira Advogados. E-mail: marinacorreiaf@gmail.com

4 Graduanda em Direito na UnB. Membro do Grupo de Estudos e Pesquisa em Segurança Internacional (UnB).

E-mail: mavisoldatelli@gmail.com 
em vista a necessidade de cooperação e transparência na relação entre os atores sociais, econômicos e políticos, a fim de que se garanta o acesso à água. Nesse contexto, o aperfeiçoamento da regulação para que se assegure $o$ direito à informação, transparência e de acesso à água, bem como a atuação do Ministério Público em defesa do meio ambiente, são essenciais para o enfrentamento da crise hídrica.

Palavras-chave: crise hídrica; governança hídrica; Política Nacional de Recursos Hídricos; São Paulo.

\section{SOCIETAL ACTION CONCERNING THE FAILURE OF STATE GOVERNANCE IN THE CASE OF THE SÃO PAULO WATER CRISIS (2013-2015)}

\section{Abstract}

The objective of the article is to analyze societal action regarding the governance failures of the state in a water crisis situation. To this end, the research is based on the study of the São Paulo water crisis case, between 2013 and 2015, supported by the deductive method and the national normative analysis technique in connection with jurisprudence, literature review and reports on the Sáo Paulo case. Once the main governance failures of the State have been noted, it is investigated how society can organize itself and act to deal with the water crisis and, likewise, what are the main contributions of the Law to the treatment of the crisis. The results of the investigation highlight the need to improve the participatory model of water management, bearing in mind the need for cooperation and transparency in the relationship between social, economic and political actors, in order to guarantee access to water. In this context, the improvement of regulation to secure the right to information, transparency and access to water, as well as the action of the Public Prosecutor's Office in defense of the environment, are essential to face the water crisis.

Keywords: National Water Resources Policy; São Paulo; water crisis; water governance. 


\section{Introdução}

$\mathrm{O}$ acentuamento das crises hídricas revela fragilidades na proposta de gestáo integrada dos recursos hídricos, uma vez que, nesse cenário, as múltiplas esferas de governança da água passam a atuar de maneira centralizada e náo participativa. Diante dessa configuração, o que se verifica é o acentuamento dos problemas acarretados pela crise e, em alguns casos, o estabelecimento de conflitos pelos usos da água para o abastecimento humano e o uso setorial, principalmente o industrial, o de irrigação e o de geração de energia elétrica (FERRAÇO, 2019).

Nesse cenário, a proposta da governança hídrica é a de superar a representação do Estado como o único encarregado da gestão da água, permitindo que os demais atores sociais sejam incluídos nos espaços de tomada de decisóes relacionadas à água. É a maneira como atores públicos, privados e sociedade civil, compartilhando responsabilidades, administram esses recursos. Portanto, ocorre a partir da articulação de diversos grupos, conectando as reivindicaçóes da sociedade às açôes governamentais, de maneira a construir uma governança participativa que envolve o engajamento de ambos os setores, conjuntamente, na gerência de recursos naturais comuns (JACOBI; CIBIM; LEÁO, 2015).

Na gestáo hídrica brasileira, essa perspectiva teve como precursora a Política Estadual de Recursos Hídricos de São Paulo (PERH-SP), implementada pela Lei n. 7.663 de 1991, que tinha como princípios o gerenciamento descentralizado, participativo e integrado da água; a adoção da bacia hidrográfica como unidade físico-territorial de planejamento e gerenciamento; e o reconhecimento do recurso hídrico como um bem público com valor econômico. Mais tarde, em 1997, foi instituída a Política Nacional de Recursos Hídricos (PNRH) pela Lei Federal n. 9433, que, com inspiraçóes na PERH-SP, estabeleceu que a gestão dos recursos hídricos deve ser descentralizada e contar com a participação do Poder Público, dos usuários e da comunidade. Desse modo, consolidou-se o fortalecimento de governança hídrica multinível, refletida nos fundamentos da legislação estadual e federal sobre recursos hídricos.

Diante da configuração multinível da governança hídrica, torna-se relevante investigar eventuais falhas do Poder Público para com esta, a exemplo da falta de planejamento e investimentos adequados. Como consequência dessas falhas, a sociedade civil passa a encontrar meios de suprir a insuficiência estatal, com a finalidade de mitigar os efeitos da crise. A partir dessa configuração, o objetivo deste artigo é o de analisar a atuação da sociedade mediante as falhas de governança do poder público estatal em situação de crise hídrica.

O conceito de sociedade civil utilizado neste artigo encontra fundamento na teoria de espaço público de Habermas. A sociedade civil se diferencia das esferas da economia e do Estado e atua não somente de modo defensivo em relação a essas estruturas sistêmicas, mas também pode influenciar o Estado e a economia na 
manutenção de direitos que constituem a condição sine qua non de sua existência (ARATO; COHEN, 1994). A sociedade civil sob uma perspectiva habermasiana é considerada sociedade civil social, em que prepondera o papel dos novos movimentos sociais (a exemplo das ONGs) em relação às representaçôes políticas e sociais tradicionais como os partidos políticos e os sindicatos. No contexto do caso da crise hídrica de São Paulo, a sociedade civil analisada neste estudo é composta pelas instituiçóes não estatais, sejam elas institutos de estudo e pesquisa, organizaçôes do terceiro setor, organizaçôes privadas ou até mesmo a população paulista.

Nesse sentido, investiga-se qual a responsabilidade do poder público em relação às falhas de execução no gerenciamento hídrico, e, mais além, como a sociedade civil passa a atuar diante da incapacidade estatal, por ação ou omissão, ao desempenhar o papel fundamental e centralizado no contexto da governança hídrica.

Um importante caso nacional, capaz de fornecer o substrato necessário para essa análise, foi a crise hídrica que assolou o estado de São Paulo, entre os anos 2013 e 2015. A diminuição das chuvas no estado de São Paulo ao final de 2013, estendendo-se pelos anos de 2014 e 2015, provocou a redução da oferta de água nas bacias hidrográficas que abastecem a Região Metropolitana de São Paulo (RMSP), composta por 39 municípios que compreendem uma população de mais de vinte milhôes de habitantes.

Entretanto, não se pode abordar a crise exclusivamente pela perspectiva climática, uma vez que o descaso das autoridades e instituiçóes públicas para com a governança da água está no centro do problema (JACOBI; CIBIM; LEÃO, 2015). Muitos fatores políticos e institucionais contribuíram para a magnitude da crise que se instaurou na regiáo, de tal modo que a análise jurídica dessas questôes possibilita trazer resposta para um melhor enfrentamento de crises semelhantes.

Para cumprir esse fim, o presente artigo analisa o caso da crise hídrica de São Paulo, situada temporalmente entre os anos de 2013 e 2015, com o amparo do método dedutivo. A técnica de pesquisa empregada nesta investigação é a análise normativa nacional de modo dialogado com a jurisprudência, e a revisáo bibliográfica, junto aos relatórios sobre o caso de São Paulo. A partir da análise realizada, num primeiro momento, buscou-se demonstrar as falhas de planejamento e gestão para a prevenção da crise hídrica e, em seguida, foram apresentadas as formas de organização e ação social para o enfrentamento de crise a partir da atuação da sociedade civil. Por fim, destacaram-se as contribuiçóes do Direito para o tratamento da crise hídrica, a partir do caso de São Paulo.

A pesquisa aponta para a necessidade de aperfeiçoamento do modelo participativo de gestáo da água no cenário de governança no enfrentamento da crise hídrica. Entre as principais falhas de atuação do Poder Público Estatal, destaca-se a necessidade de cooperação e transparência, a fim de que se garanta o acesso à água em detrimento dos interesses políticos e econômicos. Nesse contexto, o Direito apresenta um papel de destaque, aprimorando a regulação hídrica para que se assegure o direito à informaçáo, à transparência e ao acesso à água, bem como pela atuação do Ministério Público em defesa do meio ambiente. 


\section{A fragilidade do planejamento e gestáo do abastecimento de agua no estado de Sáo Paulo como determinante para a crise hídrica}

A diminuição das chuvas no estado de São Paulo provocou a redução da oferta de água nas bacias hidrográficas que abastecem a Macrometrópole Paulista (MMP). No entanto, a crise não deve ser abordada somente por sua faceta climática, sendo necessário que a discussão seja direcionada para a responsabilidade do poder público em relação à implementação da política de gestão dos recursos hídricos.

Os incidentes relacionados ao clima têm atingido as cidades brasileiras com uma regularidade crescente, mas continuam, invariavelmente, sendo aludidos pelas autoridades como fatalidades, catástrofes e tragédias, resultado de fenômenos climáticos incomuns. $\mathrm{O}$ repertório de termos utilizados para reduzir esses eventos a situaçóes imprevisíveis e inevitáveis é extenso. Contudo, há pouco de imprevisível ou inevitável nos desastres: são consequências da fragilidade institucional do poder público, que perpetua um padrão de gestão urbana no qual o planejamento é substituído por operações emergenciais (RIBEIRO, 2011).

Nesse sentido, apesar de revestida por novos elementos, a crise de abastecimento que atingiu a região de São Paulo tem raízes muito mais profundas que o período de 2013 a 2015, em que a estiagem chegou a seu ápice - documentos históricos demonstram que a insegurança hídrica assombra o estado há pelo menos três séculos. Desde então, crises foram constantes. A atuação dos governantes, todavia, manteve-se aquém do adequado para solucioná-las, na maioria das vezes ocorrendo sem o planejamento necessário (CUSTÓDIO, 2015).

É importante, destarte, analisar como se deram as açóes dos agentes envolvidos na gestáo dos recursos hídricos nos anos que precederam sua crise mais recente, denotando sua insuficiência e contrapondo tais açóes às recomendaçóes apresentadas por especialistas na área. $\mathrm{O}$ mesmo deve ser feito em relação à resposta imediata do poder público quando a crise eclodiu, abalada pela proximidade do período eleitoral, e ao tardio e controverso plano de contingência apresentado pelo estado.

\subsection{A lógica de operação da Sabesp e sua responsabilidade pela insuficiência de investimentos no sistema de captaçáo nos anos que precederam a crise}

A necessidade de mudanças no sistema de abastecimento na Regiáo Metropolitana de Sáo Paulo (RMSP) já vinha sendo evidenciada por documentos oficiais, que a caracterizavam como vulnerável à escassez de água (JACOBI; CIBIM; LEÃO, 2015). A vulnerabilidade é uma condição determinada não somente por forças da natureza, mas também pelos sistemas sociais (WISNER et al., 2003). 
Por sua vez, a escassez hídrica é determinada pela indisponibilidade da água, consequência da reduçáo acentuada na precipitação pluviométrica por período de tempo prolongado, provocando um desequilíbrio hidrológico crítico (CASTRO et al., 1998).

Nesse viés, variaçôes de precipitação podem resultar em riscos ao sistema de abastecimento de regióes urbanas que dependem excessivamente de uma quantidade mínima de chuvas para mantê-las. É importante ressaltar que a precipitação média histórica, parâmetro estabelecido a partir de uma medição mensal que registra a média de chuvas de um período definido, oferece somente uma expectativa, mas não há como garantir que esta perdurará sem variaçôes (SORIANO et al., 2016).

Pela análise desses fatores, a saída para a insegurança hídrica na região Sudeste do Brasil requer o planejamento preventivo em situaçóes extremas de escassez hídrica e falhas nos sistemas de abastecimento, devendo ser "permanente, abrangente e prever um conjunto de açóes para cada estado hidrológico e as respectivas responsabilidades, a fim de reduzir os impactos" (BICUDO et al., 2015, p. 15). As medidas de prevenção para situações de escassez de água precisam ser empregadas de maneira continuada e definitiva, contando com planos de preparo para o enfrentamento desses eventos, assim como o estabelecimento de responsabilidades dos agentes e instituiçóes envolvidas.

No caso de Sáo Paulo, o governo foi alertado pelo Departamento de Águas e Energia Elétrica (DAEE), ainda em 2004, sobre a imprescindibilidade de se diminuir a dependência em relação ao Sistema Cantareira, cuja concessão era pleiteada pela Sabesp, indicando que o crescimento populacional na metrópole paulista havia limitado a capacidade do reservatório para abastecê-la. Contudo, entre 2008 e 2013, menos investimento do que o previsto foi destinado pela empresa às obras para expandir a oferta hídrica (JACOBI; CIBIM; LEÃO, 2015).

Esse fato foi de encontro à situação financeira da Sabesp - uma das 20 mais rentáveis do Brasil e uma das 25 maiores empresas de saneamento do mundo -, que, durante os sete anos que antecederam 2014, lucrou quase 10 bilhóes de reais. Somado a isso, a empresa é extremamente generosa na distribuição de dividendos a seus acionistas: enquanto o valor mínimo legal de pagamento corresponde a $25 \%$ do lucro obtido, a quantia partilhada superou-o em $48 \%$, como revelou Figueiras (2014), segundo a qual o governo de São Paulo, acionista majoritário da companhia, estando em posse de 50,3\% das açóes, foi o maior beneficiado pelo grandioso retorno em dividendos (FIGUEIRAS, 2014).

Os cerca de 1,7 bilhão de reais restantes para investimentos anuais foram gastos, em grande parte, para a expansão dos negócios da empresa, buscando aumentar sua clientela, ultrapassando 1 milhão de novas ligaçôes em um período de cinco anos (FIGUEIRAS, 2014). Operando a partir de uma lógica de obtenção de lucros, quanto mais água fornecida, maior seria seu rendimento - mesmo que isso 
signifique a utilização desenfreada de suas reservas de água. Isso foi evidenciado especialmente pelos contratos de demanda firme firmados pela Sabesp desde 2002 com estabelecimentos industriais e comerciais que consumissem mais de $500 \mathrm{~m}^{3 /}$ mês de água que, em função dos altos custos do abastecimento, utilizavam o serviço da empresa de maneira mínima (CUSTÓDIO, 2015).

Para fidelizá-los, a companhia fornecia planos de consumo mínimo, que seriam pagos integralmente mesmo que a quantidade utilizada fosse mais baixa. Se a ultrapassasse, somente pagaria a diferença. Na prática, as empresas que economizassem água eram penalizadas, operando em uma lógica contrária à imposta à população (CUSTÓDIO, 2015). Enquanto isso, os gastos com a redução de perdas e investimentos em novas fontes de captação foram muito menores, resultando em uma taxa de desperdício no sistema na casa dos 36\%, cerca de 435 bilhóes de litros por ano (FIGUEIRAS, 2014).

Existe uma questão de injustiça em termos de equidade ambiental (BEDER, 2000) nas açôes da Sabesp em relação a seus diferentes contratos direcionados para diferentes tipos de consumidores. Embora a equidade ambiental possa se relacionar à adoção de medidas para garantir a sustentabilidade, os mecanismos de mercado utilizados pela Sabesp reforçaram desigualdades entre os destinatários finais da água.

A equidade ambiental reforça a ideia de que tais políticas devem ser aplicadas de modo imparcial, equilibrado e equânime para a configuração da garantia de acesso e oportunidade do recurso. Há, pois, no caso da Sabesp, o racionamento de água para alguns e a manutenção privilegiada dos níveis de consumo para outros. Do mesmo modo, aqueles que utilizam água para abastecimento humano e consumo próprio estavam pagando mais do que aqueles que utilizam a água para atividades de fins comerciais (FERRAÇO, 2019).

Portanto, as condiçôes de concessão do Sistema Cantareira não foram cumpridas pela Sabesp, não sendo realizados os investimentos estipulados para diminuir a dependência da regiáo em relação ao sistema, o que, segundo os Ministérios Públicos Estadual e Federal, levou à grave crise de abastecimento na região. Além disso, a forma de operação da companhia, voltada para o aumento do lucro em detrimento do investimento em obras necessárias, tornou a situação ainda mais dramática (SORIANO et al., 2016).

Assim, a dependência em relação a uma quantidade pluviométrica mínima para evitar o colapso do sistema de abastecimento foi mantida, não havendo como prepará-lo para o período de estiagem que atingiu São Paulo no final de 2013. Além disso, o quadro político-institucional à época da eclosão da crise foi determinante para a lentidão nas respostas por parte do governo. Como será explorado no tópico seguinte, com a proximidade das eleiçóes de 2014, a tentativa desesperada de evitar a perda de eleitores comprometeu o enfrentamento à crise hídrica que seu instaurou. 


\subsection{O cenário político-institucional como óbice à mitigação da crise}

A evolução tecnológica ainda não permite que situaçôes climáticas extremas possam ser totalmente evitadas, mas a magnitude de seus resultados pode ser atenuada de maneira substancial por medidas de mitigação, entendidas como a redução ou minimização dos impactos adversos de um evento perigoso (UNISDR, 2009). São estratégias dirigidas para enfrentar cenários mais agressivos, nos quais as medidas de prevenção adotadas não são mais suficientes para evitar o cenário de crise (SORIANO et al., 2016). Em Sáo Paulo, a elaboração de medidas de mitigação para o iminente surto de escassez de água sofreu com a fragilidade do cenário político-institucional brasileiro.

As chuvas até $30 \%$ acima da média entre 2008 e 2013 sustentaram por um longo tempo um sistema que operava no limite, mas sua fragilidade foi exposta em poucos meses de período seco: em março de 2014, o nível do Sistema Cantareira chegou a 14,6\%, o mais baixo desde sua criaçáo (BARIFOUSE, 2014). Em maio, relatórios da Agência Nacional de Águas (ANA), do Departamento de Águas e Energia Elétrica (DAEE) e do Comitê das Bacias dos Rios Piracicaba, Capivari e Judiaí (PCJ) alertavam que o fornecimento de água nas taxas de consumo da época só estaria assegurado até novembro daquele ano. Entretanto, o Governador Geraldo Alckmin, acompanhado pelo Secretário de Saneamento e Recursos Hídricos, continuava a afirmar que não existia necessidade de racionamento de água (SORIANO et al., 2016).

A insistência dos gestores em omitir a dimensão da crise hídrica se manteve mesmo quando a população passou a questioná-los. Muitas regiôes da Grande São Paulo passaram a ser afetadas pela escassez de água, atingindo cerca de $35 \%$ de sua população, ainda que o governo negasse que estivesse executando racionamentos. A divulgação desses dados, obtidos por um levantamento do Instituto Data Popular, levou o partido de Alckmin a declarar que a justiça eleitoral seria notificada sobre a pesquisa, uma vez que, por tratar-se de um ano de eleiçóes, a publicação de tais informaçóes poderia ter impactos negativos na campanha do então governador à reeleição (SORIANO et al., 2016).

Em contraste com as açóes do poder público, especialistas afirmam que reconhecer publicamente e conscientizar a população sobre a magnitude da crise é um dos componentes estratégicos a seu enfrentamento. Uma situação como esta afeta não somente o abastecimento público, mas a saúde da população e a economia como um todo, uma vez que a qualidade da água e sua disponibilidade estão severamente reduzidas. Nesse contexto, o direito ao acesso à informação deve ser assegurado aos cidadáos, devendo esta ser disponibilizada de maneira franca e integral, contendo dados atualizados. A transparência é essencial para evitar uma maior instabilidade social nas regiôes afetadas (BICUDO et al., 2015).

É importante denotar que um sistema de governança hídrica necessita, também, da participação integrada da população no combate à crise, de maneira a 
mobilizá-la para reduzir o consumo e apoiar as açóes executadas pelo poder público, atendendo as demandas sociais (JACOBI; CIBIM; LEÃO, 2015). Além disso, em vez de racionamento, medidas de racionalização de água poderiam ser implementadas, sendo algumas delas:

[...] reduçấo da oferta para uso agrícola (acompanhada de compensaçóes aos agricultores), restriçóes para calçadas e lavagem do carro, e para outras empresas que requerem uso intensivo de água (com compensação aos empresários), os incentivos financeiros (isenções fiscais, financiamento facilitado, etc) para a implementação de sistemas individuais para o uso de água da chuva e reuso da água, incentivos para a investigação, desenvolvimento e implementação de sistemas para a redução do consumo de água (SORIANO et al., 2016, p. 32).

Em São Paulo, para evitar o racionamento, a Sabesp implantou, em fevereiro de 2014, um desconto na conta de água para os clientes que reduzissem seu consumo, concedido proporcionalmente ao percentual de diminuição (ECONOMIA DE ÁGUA..., 2015). O desconto foi ampliado em outubro do mesmo ano, quando o nível do Sistema Cantareira chegou a 3\% de sua capacidade (SABESP AMPLIA..., 2014), somente um mês antes do que a ANA, DAEE e Comitê CNJ alertaram ser o limite para o abastecimento normalizado na região.

$\mathrm{O}$ bônus, aliado à utilização de válvulas redutoras de pressão, levou a uma diminuição de $20 \%$ na demanda por água (PORTO, 2015). Entretanto, a estratégia recebeu críticas, uma vez que, além de trazer o risco da Sabesp ser descapitalizada, "a utilização de um prêmio por uma ação paliativa foi uma alternativa questionável ao racionamento, porque a redução do consumo não foi suficiente" (SORIANO et al, 2016, p. 32).

Nota-se que a capacidade do estado de São Paulo em mitigar a crise hídrica foi duramente comprometida pela proximidade das eleiçóes, sendo a magnitude da crise hídrica omitida da população devida ao receio quanto aos impactos negativos à campanha de Geraldo Alckmin à reeleição. As medidas adotadas, ainda que contassem com forte engajamento da população, não foram suficientes para gerar a economia de água necessária, obrigando o poder público a elaborar um plano de contingência, o qual foi apresentado com meses de atraso.

\subsection{A preparação e a resposta do poder público à crise hídrica}

A capacidade de preparação e resposta do poder público é crucial para o enfrentamento de uma crise hídrica, especialmente quando considerada a magnitude da crise que atingiu Sáo Paulo. Construir e implementar um plano 
de contingência imediatamente é crucial para o gerenciamento da crise, devendo ocorrer de maneira urgente, contando com medidas emergenciais que atinjam todos os usuários de maneira equitativa (BICUDO et al., 2015). No âmbito de uma situação de seca, a elaboração de um plano de contingência pode ser entendida como uma medida de preparação, que, de acordo com a Organização das Naçóes Unidas, é definido como:

O conhecimento e as capacidades desenvolvidas por governos, resposta profissional e organizaçôes de recuperação, comunidades e indivíduos a antecipar de forma eficaz, responder e de recuperar, os impactos de eventos ou condiçôes de perigos prováveis, iminentes ou atuais (UNISDR, 2009, p. 21).

Nesse sentido, o governo do estado demonstrou, novamente, a incapacidade do poder público em atuar em situações extremas, especialmente em razão da falta de estrutura e planejamento para gestão dos recursos hídricos, além do quadro político-institucional brasileiro. Sáo Paulo apresentou o Plano de Contingência de maneira assustadoramente tardia, uma vez que a crise já havia se estabelecido no estado, vindo a apresentar o plano somente em novembro de 2015 (LEITE, 2015).

O plano considerava açôes em três níveis, respectivamente: atenção, alerta e emergência. O primeiro, a ser adotado quando houver sinais de estiagem prolongada, que configura uma situaçáo de risco elevado de náo ser atendida a demanda de água. O segundo, nível 2, deve ser adotado quando os sistemas de abastecimento alcançarem níveis críticos, podendo comprometer a curto prazo o atendimento à demanda de água da Regiáo Metropolitana de São Paulo, ou seja, o risco de não atendimento é elevado. O nível 3, adotado na iminência do não atendimento da demanda, quando um ou mais sistemas de abastecimento estejam sob elevado risco de esvaziamento crítico, comprometendo o abastecimento de parte da população com grau de severidade significativo (CCH, 2015).

Em resumo, no nível de atenção são apontadas as áreas que correm risco de serem atingidas pela escassez de água, sendo intensificados os esforços para a realizaçáo de adaptaçóes no sistema de abastecimento para reduzir o desperdício, assim como um aumento da fiscalização de ligaçôes irregulares e de vazamentos nas instalaçôes. O nível de alerta tem como objetivo intensificar as açóes do primeiro nível, assim como a implantação do plano de contingência setorial. Por fim, no nível de emergência são feitos os cortes sistemáticos no abastecimento hídrico, medida para impedir a falência total de um ou mais dos sistemas produtores de água (CCH, 2015).

A execução do plano de contingência foi feita a partir da redução da pressão na rede de distribuição, além da diminuição da captação de água do Sistema Cantareira para possibilitar a recuperação de seus níveis durante o período de chuvas (SORIANO et al., 2016). Essa ação pode ser entendida como uma fase 
de resposta, cujo foco, majoritariamente, destina-se às necessidades imediatas e de curto prazo para enfrentar a situação de crise. São medidas adotadas "durante ou imediatamente após um desastre para salvar vidas, reduzir impactos na saúde, garantir a segurança pública e atender à subsistência básica, necessidades das pessoas afetadas" (UNISDR, 2009, p. 28).

Enquanto o plano não era posto em prática, o estado de São Paulo respondeu à crise com a utilização do volume morto - quando o nível do reservatório fica abaixo das comportas da barragem que o forma - do Sistema Cantareira, cuja captação passou a ser a diminuída com o uso de outros reservatórios, como o Sistema Guarapiranga, em melhor situação hídrica, reduzindo em quase 3 milhões a quantidade de pessoas atendidas pelo primeiro. Além disso, adotou o sistema de racionamento, com a diminuição parcial da oferta de água distribuída, no regime de rotação ou restrições de horários e/ou fluxos de abastecimento, sem implicar a escassez na íntegra a qualquer grupo, por um período superior a três dias (SORIANO et al., 2016).

\section{A atuaçáo da sociedade civil diante da falta de governança hídrica pelo Estado}

Em um contexto de crise hídrica, diante da falha por parte dos gestores públicos em dar respostas ao problema e em pôr em prática formas de governança hídrica, várias iniciativas surgiram a partir da organização da sociedade. Diante das falhas de gerenciamento do governo de São Paulo, foi essencial a atuação direta da sociedade, por meio de medidas de enfrentamento à crise. Nesse sentido, atores privados e os próprios cidadáos paulistas reclamaram o direito à informação, transparência e de acesso à água, aos quais a população foi privada durante o período de crise hídrica em São Paulo, bem como apresentaram medidas de curto, médio e longo prazo para o enfrentamento da questáo hídrica.

\subsection{A atuação da sociedade civil para o acesso à informação no cenário de crise hídrica}

Entre as iniciativas que surgiram diante da falta de transparência e informação, a organização não governamental Instituto Democracia e Sustentabilidade (IDS), em conjunto com o Programa de Pós-Graduação em Ciência Ambiental do Instituto de Energia e Ambiente da Universidade de Sáo Paulo (Procam/IEE/ USP), criaram o projeto $A$ crise hidrica e a mídia, por meio do qual se realizou um levantamento de notícias veiculadas sobre a crise nos principais jornais do estado de São Paulo com o intuito de verificar como foi a comunicação sobre a crise em Sáo Paulo, suas causas, soluçóes e agentes envolvidos (IDS, 2014b). Durante sua primeira fase, realizada em 2014, a pesquisa mostrou que, de um total de 
196 notícias avaliadas, a maioria reproduz o discurso oficial, fazendo referência a organizaçôes públicas, tais como a Sabesp, a Agência Nacional de Águas e o Governo do Estado de Sáo Paulo, enquanto a sociedade civil, a academia e instituições privadas são consultadas com frequência consideravelmente menor (IDS, 2014b).

Além disso, verificou-se que a estiagem é apresentada como a causa principal da crise na maioria das notícias, e questôes como má gestão e planejamento, negligência, desperdício e desmatamento são pouco abordadas. Quanto às soluçôes, poucas notícias analisadas apresentaram propostas, e entre as que expuseram, $46 \%$ tratavam de medidas imediatas e urgentes e $28 \%$ de planejamento (IDS, 2014b). Esses resultados demonstram como a imprensa abordou o problema da seca de maneira limitada, deixando de lado atores importantes para a solução da crise hídrica e não dando a devida importância para a questáo da governança.

A mesma iniciativa também chegou a realizar uma mesa redonda intitulada Políticas públicas e escassez hidrica no estado de São Paulo: governança, transparência e alternativas para a crise, cujo objetivo era de "identificar atores que deveriam ter papel relevante nesse contexto e identificar as soluçôes de curto, médio e longo prazo que devem ser tomadas e por quais instituiçôes, além de se pensar nas melhores estratégias para a sensibilização da população" (IDS, 2014b).

Já o Artigo 19 é uma organização não governamental que atua a favor da transparência e prestação de contas, avaliando as práticas de transparência governamental e seus dispositivos de acesso à informação, e realizando campanhas pela divulgação de informação de interesse público. No que diz respeito à seca em São Paulo, o Artigo 19 lançou em 2014, no auge da crise, o relatório Sistema Cantareira e a Crise da Água em São Paulo: a falta de transparência no acesso à informação, no qual foi analisado o grau de transparência no acesso e no conteúdo das informaçôes disponíveis sobre a crise da água nos sites oficiais das instituiçôes e órgãos envolvidos com a problemática. A análise realizada foi qualitativa, feita a partir do tipo de informação encontrada nos sítios digitais (como documentos/informativos técnicos, documentos oficiais, boletins de notícias, atas de reunióes) e baseada em três critérios: acessibilidade, qualidade e compreensibilidade da informação. Observou-se que o site do governo do Estado de São Paulo não apresentava nenhuma informação acerca da crise da água, enquanto as informaçôes disponíveis sobre o sistema Cantareira no site da Sabesp se resumiam a dados técnicos sobre o volume de água remanescente nas médias do sistema e de chuva (ARTIGO 19, 2014).

Posteriormente, em 2016, o Artigo 19 lançou outro relatório sobre o problema Sistema Cantareira e a Crise da Água em São Paulo: falta de transparência, um problema que persiste, mostrando que, apesar de haver melhora em relação a 2014, o óbice ainda persistia. Esse relatório utilizou o mesmo método de análise que o de 2014, e observou que alguns órgãos aumentaram a transparência de seus sites, tais como a Sabesp e o do Governo do Estado de São Paulo, que passaram a 
fornecer mais informaçóes. Esse aumento de transparência se deu principalmente após a atuação do Ministério Público. No entanto, o relatório apontava para um esforço do Governo do Estado em minimizar a gravidade da questão por razóes de interesses políticos (ARTIGO 19, 2016).

O Instituto Brasileiro de Defesa do Consumidor (IDEC) atuou em meio à crise hídrica lançando a campanha Tô sem água, com o intuito de verificar os locais em que estava faltando água e cobrar mais transparência do governo em relação ao racionamento. O Instituto também acionou o Ministério Público contra a Sabesp, diante de situação em que a companhia não enviou o mapa da diminuição noturna da pressão da água. Além disso, em seu site, o IDEC (2014) mantinha informaçôes sobre os direitos dos cidadãos face à falta de água e caminhos a percorrer para exercê-los.

Uma vez que é necessário garantir a transparência e o acesso à informação para a sociedade para que seja possível o efetivo engajamento da população nos processos de tomada de decisão, percebe-se a extrema importância da atuação das organizaçôes civis para o acesso à informação sobre a crise hídrica de modo acessível e crítico. A resposta das organizaçôes perante a insuficiência de informação pública, representa uma importante alternativa. As informaçóes coletadas e analisadas pelas instituiçôes possibilitam o acesso e compreensão das informaçôes sobre a conjuntura geral da crise, assim como a maneira cuja crise afeta diretamente a população e o que pode ser feito para melhorar esse cenário.

Segundo Jacobi, Cibim e Leão (2009), um dos maiores desafios na governança hídrica atualmente é garantir uma abordagem aberta e transparente. Nesse sentido, os projetos citados servem como garantia de melhora da governança hídrica, visto que esta apresenta como fator de qualidade a participaçáo pública, a qual depende diretamente de transparência e acesso a informaçóes.

\subsection{As propostas da sociedade civil para o enfrentamento da crise hídrica}

Outra organização da sociedade civil que promoveu iniciativas diante da crise de água foi o Instituto Socioambiental (ISA), o qual é composto por coletivos, movimentos sociais, ONGs e ativistas que defendem a água como um bem comum global e um direito humano. Esse Instituto iniciou o projeto Água@SP, que pretendia mapear atores e propostas que pudessem contribuir para enfrentar a crise da água em Sáo Paulo. O projeto apresentou em 2014 um estudo que reunia 196 propostas de açôes de curto prazo, de caráter emergencial, e outras 191 açóes de longo prazo, pautadas nos princípios de cuidar, reduzir, tratar e reutilizar; e de transparência, apresentando um novo modelo de gestão da água que garanta segurança e sustentabilidade hídrica.

Como desdobramento desse projeto, foi criada a Aliança pela Água, uma 
articulação da sociedade civil que propóe uma nova cultura de cuidado com a água e cujo objetivo era contribuir com a garantia da segurança hídrica no estado. Nas eleiçóes municipais de 2016, o grupo elaborou o projeto de lei Política de Segurança Hídrica Municipal, com a campanha \#VotePelaÁgua, cujo intuito era de inserir o tema água no debate eleitoral. Além disso, como parte da campanha, foi lançado um manifesto pela água, intitulado Nova Cultura de Cuidado com a Água, ao qual diversas pessoas, entidades, movimentos, ONGs e institutos aderiram (ALIANÇA PELA ÁGUA, 2016).

Outra iniciativa foi a realização da Assembleia Estadual da Água, que reuniu coletivos, movimentos sociais, ONGs e ativistas para discutir a crise e meios de solucioná-la por meio da mobilização social. Em uma das Assembleias foi questionada a falta de transparência do governo de São Paulo no que diz respeito à crise hídrica e às obras autorizadas sem o devido conhecimento e controle dos cidadãos.

No mesmo sentido, o Instituto Akatu, uma organização não governamental sem fins lucrativos, buscou oferecer respostas por meio da educação ambiental. O instituto atua na conscientização e mobilização da população para o consumo consciente e a mudança para estilos mais sustentáveis de vida, priorizando a educação e a comunicação, a partir do desenvolvimento de campanhas, pesquisas e eventos (Livro branco da água, 2018). Uma das formas de atuação do Instituto foi a promoção, em parceria com a Braskem (empresa química e petroquímica brasileira), da plataforma Edukatu, uma rede online de aprendizagem sobre consumo consciente e sustentabilidade, que trouxe como um dos temas a crise hídrica. Durante a seca o Instituto também lançou a campanha \#águapedeágua, que buscava mobilizar a sociedade para o consumo consciente da água (EDUKATU DISPONIBILIZA..., 2016).

Nesse aspecto, importa ressaltar que, embora o consumo consciente e a racionalização do uso da água pela população desempenhem um importante papel diante das limitaçóes impostas pela escassez, a responsabilidade pelo gerenciamento dos recursos hídricos, a fim de que seja assegurada água em quantidade e qualidade, é do Poder Público. Diante disso, a PNRH, em seus arts. 11 e 12, prevê o regime de outorga de direitos de uso de recursos hídricos como importante instrumento de racionalização dos usos da água, cuja concessão é de competência do Poder Público, a fim de assegurar o efetivo exercício dos direitos de acesso à água.

Durante o período de seca surgiu também o Movimento Cisterna Já, uma iniciativa da sociedade civil, com cidadáos preocupados em propor uma alternativa emergencial para a crise, e cuja atuação era a de ensinar as pessoas a fazerem suas próprias cisternas, promovendo a capacitação para a captação e aproveitamento da chuva (ZOROWICH, 2014). No mesmo contexto também atuou o Movimento Gota D’Água, que promovia divulgação de informaçôes e alternativas de solução para a crise da água em São Paulo.

Outra entidade que vem atuando para enfrentar a crise da água é o Instituto 
de Pesquisas Ecológicas (IPE), por meio do Atlas dos Serviços Ambientais do Sistema Cantareira, que indica que, atualmente, 61,6\% da área do Sistema é dominada por açóes antrópicas, como áreas urbanas e pastagens em pequenas propriedades. Nessa área, a água da chuva não é devidamente absorvida e, assim, não abastece os lençóis freáticos. Diante desse problema, a Sabesp mantém o programa de reflorestamento Cinturão Verde dos Mananciais Metropolitanos que, nos últimos anos, plantou milhóes de mudas.

Diante disso, o Instituto IPE criou um projeto que atua com medidas a longo prazo, como é caso do programa Semeando Água, com o objetivo de disseminar práticas sustentáveis junto aos produtores rurais da região, de modo a ampliar a conservação dos recursos hídricos e também aumentar a renda desses produtores. O projeto atua em cinco frentes: restauração florestal, educação ambiental, manejo de pastagem ecológica, políticas públicas e comunicação (PRIZIBISCZKI, 2019).

Todas essas iniciativas privadas mostram a capacidade de articulaçáo e mobilização da sociedade civil na busca de cooperação com o governo. A ampliação desses tipos de práticas fortalece a corresponsabilização dos atores, estimulando o desenvolvimento de práticas que tragam alternativas e soluçóes para os problemas que surgem em torno de bens comuns, como é a água (JACOBI; CIBIM; LEÃO, 2015). Além disso, a atuaçáo organizada da sociedade civil nesse contexto de crise hídrica em Sáo Paulo representa uma possibilidade de mudança da lógica de gestão e da administração pública, uma vez que frequentemente os entes públicos protagonizam os acontecimentos e a população é deixada de lado, tanto em ter acesso a informaçóes efetivas e detalhadas acerca da situação, quanto no que diz respeito a assumir responsabilidades diante do problema. Assim, abre-se espaço para a participação da sociedade, com maior integração entre governo, população e organizaçôes privadas, a fim de garantir maior governança hídrica.

\section{0 equacionamento da crise hídrica a partir da proteção jurídica do meio ambiente no caso de Sáo Paulo}

O Direito apresenta importantes contribuiçôes para o equacionamento de cenários de crise hídrica, por meio da regulação ou, posteriormente, da reparação ao dano causado, diante da insuficiência das medidas administrativas para a realizaçâo satisfatória da gestão hídrica. Verificando-se o nâo atendimento dos parâmetros legais para o gerenciamento dos recursos hídricos, seja por falhas de gestáo ou por violação a direitos fundamentais relacionados ao acesso à água, a crise pode ser abordada tanto pelos instrumentos de regulaçáo hídrica quanto por meio da Ação Civil Pública ambiental. 


\subsection{A regulação como instrumento democrático de governança hídrica}

Quanto à regulação hídrica no Brasil, e principalmente no estado de São Paulo, há de se destacar a importância da democratização, durante sua criação e atuação, dos planos diretores como instrumentos de planejamento juridicamente vinculantes. A Política Nacional de Recursos Hídricos engloba os Planos de Recursos Hídricos de maneira multinível, interligando as gestóes das bacias, estaduais e nacional.

Tais planos, por sua força normativa capaz de limitar a discricionariedade administrativa, serve de instrumento para tomadas de decisóes políticas. Desse modo, a importância da atuação social em sua elaboração e fiscalização, deve ser de modo a combater a utilização de bens de domínio público a partir de interesses de grupos politicamente ou economicamente favorecidos, de modo a prezar pela efetivação das prioridades nacionais constitucionalmente estabelecidas.

O outro ponto a ser observado diante da administração dos recursos hídricos nacionais é a importância da integração entre gestôes e suas responsabilidades compartilhadas. Para isso, a Política Nacional de Recursos Hídricos prevê uma governança descentralizada e participativa, porém, na prática, os esforços não têm sido suficientes para a integração entre os atores competentes e interessados para a gestão do recurso, seja entre si ou com a sociedade (FERRAÇO, 2019).

A PNRH demarca a sustentabilidade dos recursos hídricos por meio da disponibilidade, utilização racional e integrada da água, a fim de que sejam garantidos os usos múltiplos de modo equitativo. Para isso, o art. $3^{\circ}$ da Lei das Águas formula diretrizes a serem observadas em sua implementação, demonstrando que os recursos hídricos náo podem ser geridos de maneira isolada em relação ao meio ambiente. Portanto, para que os gestores cumpram com a legislação em questão, deve haver um planejamento ambiental que compreenda a fauna (aquática e terrestre), as florestas, o uso do solo e de agrotóxicos, a instalação de indústrias, a renovação das antigas indústrias e o zoneamento ambiental das bacias hidrográficas

Do mesmo modo, devem ser feitos os planos estaduais, os quais devem, ainda, absorver as prioridades apontadas nos Planos das bacias hidrográficas que cruzem seu território. No entanto, o controle desse patrimônio público não tem êxito se a sociedade civil não for capaz de acompanhar a elaboraçáo do Plano de Recursos Hídricos e a utilização dos outros instrumentos da Política Nacional dos Recursos Hídricos.

Infelizmente, pôde-se observar uma falha por parte da gestáo estadual de São Paulo nesse quesito. Em Campinas, por exemplo, a falta de transparência por parte da SANASA sobre aspectos de gestão dos recursos hídricos municipais e de prestação de contas pública, se tornou um óbice para a plena participação da população. Segundo Paulo Antunes em Direito Ambiental, o direito ambiental, 
em seus aspectos regulatórios, depende da administração pública, a qual tem no princípio da publicidade administrativa um de seus alicerces, uma vez que o princípio democrático assegura aos cidadãos o direito de participar das discussóes para a elaboração das políticas públicas ambientais e de obter informaçôes dos órgáos públicos em relação à defesa do meio ambiente e de empreendimentos utilizadores de recursos ambientais (ANTUNES, 2017).

Como visto anteriormente, a falta de informação adequada à população se deu por interesses de grupos específicos, o que acabou impedindo o acesso qualitativo e quantitativo das águas do estado. Demonstra-se então, mais uma vez, que a presença do Poder Público no setor hídrico tem que traduzir um eficiente resultado na política de conservar e recuperar as águas independentemente de interesses políticos ou econômicos que sirvam ao lucro de uma pequena parte da população (MACHADO, 2013).

Há, ainda, os confrontos institucionais em razão dessa gestão compartilhada dos recursos hídricos. A partir da crise hídrica de São Paulo, o estado anunciou a transposição de águas entre o Rio Jaguari, afluente do Rio Paraíba do Sul, para o Sistema Atibainha-Cantareira. No entanto, por esse rio ser a principal fonte de captação do estado do Rio de Janeiro, afetando a qualidade da água nele fornecida, o MPF fluminense ajuizou duas açóes civis públicas requerendo que a ANA não autorizasse a realização da transposição antes que o IBAMA realizasse estudos ambientais que comprovassem a possibilidade de risco ao meio ambiente (FERRAÇO, 2019).

Passando pelo STF, as açóes levaram a uma tentativa de acordo entre os estados em 2015, estabelecendo condiçóes de operação do Sistema Hidráulico Paraíba do Sul, compreendendo os reservatórios então instalados na bacia, e referendando a viabilidade hidrológica da transposição das águas da bacia para o Sistema Cantareira, em Sáo Paulo. Ainda assim, a Procuradoria-Geral da República apontou que ainda havia divergências entre os entes envolvidos que náo haviam sido abarcadas no acordo e o STF remeteu as açóes à instância originária por compreender que o conflito não apresentava lesividade ao pacto federativo (FERRAÇO, 2019).

Esse caso demonstra não apenas o impacto da falta de integração horizontal da gestão dos recursos hídricos, como a atuação dos institutos jurídicos de modo a resolver conflitos acerca desse bem. Em seguida, veremos melhor como isso se dá por meio da atuação do Ministério Público como representante social garantidor dos direitos ambientais.

\subsection{O papel do ministério público na defesa na questáo hídrica de São Paulo}

A responsabilidade civil ambiental no Brasil compreende algumas teorias e princípios a fim de evitar vácuos sancionadores em relação aos danos ambientais. 
O princípio da responsabilidade baseia-se em várias declaraçôes das Naçóes Unidas sobre o meio ambiente, como a seguinte: "as administraçóes locais e nacionais, e suas respectivas jurisdiçóes são as responsáveis pela maior parte do estabelecimento de normas e aplicaçóes de medidas em grande escala sobre o meio ambiente" (Declaraçáo de Estocolmo sobre o Meio Ambiente Humano, 1972, preâmbulo, item 7).

Tendo isso em vista, a legislação brasileira prevê, na Constituição e na Política Nacional do Meio Ambiente (Lei 6.938/81), a tríplice responsabilização objetiva do poluidor pelo dano ambiental, seja a pessoa de Direito Público ou Privado.

No caso de São Paulo, diversas foram as injustiças ambientais verificadas. A Sabesp apresentava tratamento distinto aos consumidores e à indústria, ferindo a equidade ambiental, a qual deve se basear na adoçâo de medidas que garantam a sustentabilidade, por causa dos níveis de escassez que o recurso natural apresenta. Isso comumente se dá por meio de mecanismos de mercado, mas tais medidas devem ser aplicadas de modo imparcial, equânime e equilibrado para garantir o acesso ao bem (FERRAÇO, 2019).

Compreendendo que qualquer cidadáo eleitor pode intentar uma ação popular, focaremos na atuaçáo do MP na garantia dos direitos ambientais, pelo dever de intervir na proteção de interesses sociais ou individualmente indisponíveis, como previsto, principalmente, nos arts. 129 e 225 da Constituição Federal.

A falta de água e os demais problemas enfrentados pela população paulista já geraram mais de 50 inquéritos civis no Ministério Público (MP) e ações civis públicas protocoladas pelos promotores na Justiça. Alguns dos casos também vêm sendo acompanhados pelo Ministério Público Federal (MPF) e uma grande parte ainda está em andamento ou resultou na resolução de um Termo de Ajustamento de Conduta (TAC) (MPSP, 2015).

Para a formulação dos inquéritos, o Ministério Público Federal (MPF), além do Ministério Público, o Ministério Público de Contas, o Ministério Público do Trabalho e a Defensoria Pública, todos a nível estadual, fizeram uma audiência pública para reunir provas e saber como a sociedade vinha enfrentando problemas como a falta de água, esgoto e saneamento básico, a adoção das sobretaxas, ausência de transparência e informaçóes sobre a crise, aplicação de rodízio informal, racionamento implícito e redução da pressão nas regiôes mais carentes do estado, e dificuldade de acesso ao monitoramento da qualidade de água.

Dos inquéritos civis analisados, 4 foram arquivados, um deles se deu justamente pela falta de elementos que indicassem lesão a direito coletivo ou difuso que justificasse a continuidade das investigaçóes, outro porque, uma vez que as metas estabelecidas foram superadas, o MP entendeu que o prosseguimento da investigação era desnecessário (MPSP, 2015).

Entre os outros 46 inquéritos apurados, 5 resultaram no firmamento de Termos de Ajustamento de Conduta antes do ajuizamento da ação. Insta salientar 
que, por não ter homologação judicial, qualquer outro legitimado que não tenha intervindo no acordo pode propor ação civil pública (MPSP, 2015). Esse firmamento não significa transigência no cumprimento das obrigaçôes legais, uma vez que o MP não pode renunciá-las ou fazer concessóes diante de "interesses sociais e individuais indisponíveis" (art. 127, caput, da CF).

Ainda, qualquer acordo que admita o descumprimento dessas obrigaçôes não tem eficácia, podendo ter sua nulidade declarada pelos próprios intervenientes que tenham assinado o termo. Assim, os compromissos firmam o cumprimento de obrigaçôes discricionárias, as quais permitem sua análise quanto à sua conveniência e oportunidade por parte da Administração Ambiental ou do Ministério Público.

No que se refere às Açóes Civis Públicas (ACP), as demandas foram ajuizadas tendo o objetivo da defesa do meio ambiente e do consumidor, de modo que as açôes propostas pelo MPSP podem ser divididas quanto aos interesses lesados e à natureza do bem lesado. $\mathrm{O}$ primeiro diz respeito principalmente às açôes que tratavam da lesão ao patrimônio público, à qualidade da água e a falta dela.

$\mathrm{Na}$ defesa do meio ambiente e à saúde dos jurisdicionados, os principais dispositivos utilizados em sua defesa foram os arts. 196, 200 e 225 da CF, que preveem o direito à saúde, ao saneamento básico, à água de qualidade e ao meio ambiente ecologicamente equilibrado e os arts. $2^{\circ}$ e $3^{\circ}$ da Política Nacional de Recursos Hídricos, quanto à disponibilidade intergeracional de água (MPSP, 2015).

Já quanto à falta de transparência de informações e dos serviços prestados ao consumidor, as ACPs foram fundamentadas nos arts. $5^{\circ}$ e $60 \mathrm{da} \mathrm{CF}$, que dispóem sobre o acesso à informação de órgáos públicos, de interesse particular, coletivo ou geral; os arts. 50, 6º $8^{\circ}$ e 21 da Lei de Acesso a Informaçóes públicas (Lei n. 12527/2011), quanto ao acesso à informação por meio de procedimentos objetivos e ágeis, de maneira transparente e em linguagem de fácil compreensão; no art. 1ª, I, da Política Nacional de Recursos Hídricos, uma vez que tratam de dados e informaçôes relativos à água, que é um bem de domínio público; e no art. $6^{\circ}$, III, do Código de Defesa do Consumidor, quanto à informação adequada sobre os produtos e serviços.

Dessas açóes, $80 \%$ ainda estáo em andamento ou em grau de recurso, porém a eficácia das açóes depende que elas sejam propostas de modo amplo e coordenado, afirmando a presença social do Poder Judiciário para que se possa trazer a melhoria e a restauração dos bens e interesses defendidos (MPSP, 2015). Nesse ínterim, importa ressaltar que as indenizaçôes e multas processuais não vão para as vítimas diretas ou indiretas, por não visarem ressarcir as vítimas pessoais da agressão ambiental, mas recuperar ou tentar recompor os bens e interesses em seu aspecto supraindividual. Por isso, a quantia vai para o Fundo de Defesa dos Direitos Difusos (FDD), nos casos em que a ação apresente abrangência nacional, ou, se a ação for perante a justiça dos estados, para os Conselhos Estaduais, ambos 
os integrados pelo Ministério Público e por representantes da comunidade (MACHADO, 2013).

\section{Consideraçóes finais}

Durante a crise hídrica que ocorreu em Sáo Paulo no período de 2013 a 2015, houve a participação de diversos atores, tais como o governo, os meios de comunicação, empresas, organizaçóes privadas e a própria sociedade civil. A análise do contexto hídrico que se estendeu durante esse período deixa perceptível a falha do governo do estado na maneira de tratar a crise hídrica, uma vez que houve pouca transparência quanto ao que estava acontecendo, a gravidade da situação, as medidas a serem tomadas e sobre como a população foi afetada pelo período de escassez.

A segurança hídrica requer o planejamento preventivo a situaçóes extremas de escassez e a falhas nos sistemas de abastecimento a ser desempenhada de modo contínuo, de acordo com a competência dos atores estatais responsáveis. A discussão sobre a crise em São Paulo deve ser direcionada para a responsabilidade do poder público na gestão dos recursos hídricos. Crises hídricas não são situaçôes imprevisíveis ou inevitáveis, são consequências de um padrão de gestão urbana estatal que substitui o planejamento por operaçóes emergenciais.

O reconhecimento da crise hídrica paulista e a adoção de medidas de mitigação pelo Poder Público diante do iminente surto de escassez de água foram diretamente influenciados pelo cenário político-institucional brasileiro. Em um cenário de governança hídrica, esse quadro reforça a necessidade do aprimoramento da gestáo participativa e descentralizada em relaçáo à sociedade civil como um importante ator no combate à crise hídrica.

Em 2013, e até antes disso, já havia indícios da iminência de uma crise de água. Contudo, por se tratar de período muito próximo ao das eleiçôes, a situação não foi tratada com a clareza e a emergência devidas. Somente em 2014, no auge da crise, é que os meios de comunicação começaram a dar mais enfoque ao problema, assim como somente a partir de então o governo do estado e a Sabesp passaram a esclarecer a situação, as causas e medidas a serem tomadas, o que ainda ocorreu de modo pouco transparente e sem abertura para participação popular. As respostas dos gestores públicos à seca ficaram limitadas a medidas técnicas, como a utilização dos dois volumes mortos, rodízios, racionamento, programa ônus/ bônus e a transferência da reserva de outros sistemas.

Nesse sentido, diante da falta de transparência dos órgãos públicos e ausência de medidas que envolvessem participação da população, muitas iniciativas de organizaçóes e movimentos privados surgiram com propostas de enfrentamento da crise. Considerando as falhas do estado na promoção de uma governança hídrica, fez-se necessária a atuação direta da sociedade civil na reparação do problema. 
No que tange à transparência e informação, foram adotadas medidas para o levantamento de notícias veiculadas sobre a crise a fim de desmistificar as causas do período de escassez e identificar os atores públicos responsáveis para a gestáo da crise. Uma das iniciativas da sociedade civil resultou em um relatório que analisou a transparência no acesso e no conteúdo das informaçóes disponíveis sobre a crise nos sites oficiais das instituiçôes e órgãos envolvidos. Observou-se que o site do governo paulista não apresentava nenhuma informação acerca da crise da água e que as informaçóes disponíveis sobre o sistema Cantareira no site da Sabesp se resumiam a dados técnicos sobre o volume de água remanescente nas médias do sistema e de chuva. Outra iniciativa de grande relevância foi o levantamento dos locais afetados pela falta de água, o que possibilitou cobrar mais transparência do governo em relação ao racionamento, além de subsidiar a atuação do Ministério Público em relaçáo à Sabesp, quando a companhia não enviou o mapa da diminuição noturna da pressão da água.

No que se refere às soluçôes e estratégias para o enfrentamento da crise, a sociedade civil buscou apresentar medidas propositivas de ação e de mobilizaçáo da população para o consumo consciente da água. Entre as principais medidas, destacam-se o mapeamento de atores e a apresentação de propostas de ação de curto prazo e de longo prazo para a mitigação da escassez hídrica, a proposta legislativa para inserir o tema água no debate eleitoral e a Assembleia Estadual da Água para discutir a crise e meios de solucioná-la por meio da mobilização social. Além disso, foram adotadas respostas por meio da educação ambiental, promovendo uma plataforma online de aprendizagem sobre consumo consciente e sustentabilidade e para a captaçáo e aproveitamento da chuva.

Por fim, houve um aprofundamento das pesquisas sobre a crise hídrica, buscando-se informações e alternativas de solução para a capital paulista e destacando os efeitos das açôes antrópicas que impedem a devida absorção das chuvas para o lençol freático no Sistema Cantareira, o que levou à criação de um projeto para disseminar práticas sustentáveis junto aos produtores rurais da região.

Em paralelo, é importante destacar o papel do Direito diante de conflitos ambientais, em especial na questão da regulação como meio democrático de governança hídrica. Nesse contexto, a atuação das instituições democráticas do Estado de Direito, como o Ministério Público, contribui para o acesso às informaçóes pela sociedade, uma vez que vários dados só foram fornecidos à população depois de exigências feitas pela Justiça.

Nesse quesito, a falta de transparência se tornou um óbice para a plena participação da população no caso da crise hídrica de São Paulo. A publicidade das informaçóes é um dos alicerces da Administração Pública, intimamente relacionada com o Direito Ambiental, na medida em que garante aos cidadáos o direito de participar das discussôes sobre políticas públicas ambientais e possibilita a tomada de decisão pública informada. 
O cenário em questão deixou claro que há necessidade de um modelo de gestão que permita a cooperação e corresponsabilização entre os diversos atores sociais, econômicos e políticos para assegurar o acesso à água. Assim, as iniciativas propostas pela sociedade civil indicam a necessidade de melhora do cenário de governança hídrica, destacando o aspecto fundamental da adoção de uma nova estratégia de gestão integrada e participativa da água, a fim de que se confira maior espaço de atuação da sociedade tanto na tomada de decisão como no controle social das decisôes que serão implementadas.

\section{Referências}

ALIANÇA pela Água lança campanha \#VotePelaÁgua. Leia o Manifesto e saiba como aderir. Akatu, 12 set. 2016. Disponível em: https://www.akatu.org.br/ noticia/alianca-pela-agua-campanha-votepelaagua-manifesto-adesao/. Acesso em: 14 fev. 2020.

ALIANÇA PELA ÁGUA. Quem somos. 2014. Disponível em: https://www. aliancapelaagua.com.br/. Acesso em: 14 fev. 2020.

ALIANÇA PELA ÁGUA. Manifesto por uma nova cultura de cuidados com a água. 2016. Disponível em: https://www.aliancapelaagua.com.br/manifesto-por-umanova-cultura-de-cuidados-com-a-agua/. Acesso em: 14 fev. 2020.

ANA - AGÊNCIA NACIONAL DE ÁGUAS. Sistema Cantareira. Brasília, DF, 7 out. 2015. Disponível em: http://www2.ana.gov.br/Paginas/servicos/ outorgaefiscalizacao/sistemacantareira.aspx. Acesso em: 13 jan. 2020

ANTUNES, P. B. Direito Ambiental. 19. ed. São Paulo: Atlas, 2017.

ARATO, A.; COHEN, J. Sociedade civil e teoria social. In: AVRITZER, L. Sociedade civil e democratização. Belo Horizonte: Del Rey, 1994.

ARTIGO 19. A Organização. Disponível em: https://artigo19.org/a-organizacao/. Acesso em: 14 fev. 2020.

ARTIGO 19. Sistema Cantareira e a crise da água de São Paulo: a falta de transparência no acesso à informação. São Paulo, 2014. Disponível em: https:// artigo 19.org/old/wp-content/uploads/2014/12/Relat\%c3\%b3rio-SistemaCantareira-e-a-Crise-da-\%c3\%81 gua-em-S\%c3\%a3o-Paulo-\%e2\%80\%93-afalta-de-transpar\%c3\%aancia-no-acesso-\%c3\%a0-informa\%c3\%a7\%c3\%a3o. pdf. Acesso em: 28 jan. 2020.

ARTIGO 19. O Sistema Cantareira e a crise da água em São falta de transparência, um problema que persiste. São Paulo, 2016. Disponível em: https://artigo19. org/wp-content/blogs.dir/24/files/2016/06/Sistema-Cantareira-e-a-Crise-da\%c3\%81gua-em-S\%c3\%a3o-Paulo-2.pdf. Acesso em: 10 abr. 2020. 
ARTIGO 19. Relatório avalia transparência dos órgãos responsáveis pela crise hídrica em São Paulo, 2016. Disponível em: https://artigo19.org/blog/2016/06/28/ relatorio-avalia-o-que-mudou-na-transparencia-dos-orgaos-responsaveis-pelacrise-hidrica-em-sao-paulo/. Acesso em: 28 jan. 2020.

BARIFOUSE, R. Maior crise hídrica de São Paulo expóe lentidão do governo e sistema frágil. $B B C, 22$ mar. 2014. Disponível em: https://www.bbc.com/ portuguese/noticias/2014/03/140321_seca_saopaulo_rb. Acesso em: 20 jul. 2020 .

BEDER, S. Costing the earth: equity, sustainable development and environmental economics. New Zealand Journal of Environmental Law. v. 4, p. 227-243, 2000.

BICUDO, C. et al. Carta de São Paulo. Recursos hídricos no Sudeste: segurança, soluçôes, impactos e riscos. Revista USP, São Paulo, n. 106, fev. 2015. pp. 11-20.

BRASIL. Lei n. 6.938, de 31 de agosto de 1981. Dispóe sobre a Política Nacional do Meio Ambiente, seus fins e mecanismos de formulação e aplicação, e dá outras providências. Disponível em: http://www.planalto.gov.br/ccivil_03/LEIS/L6938. htm. Acesso em: 23 jul. 2020.

BRASIL. [Constituição (1988)]. Constituição da República Federativa do Brasil. Brasília, DF: Presidência da República, 1988. Disponível em: http://www. planalto.gov.br/ccivil_03/constituicao/constituicao.htm. Acesso em: 23 jul. 2020.

BRASIL. Lei n. 8.078, de 11 de setembro de 1990. Código de Defesa do Consumidor. Dispóe sobre a proteção do consumidor e dá outras providências. Disponível em: http://www.planalto.gov.br/ccivil_03/Leis/L8078.htm. Acesso em: 23 jul. 2020.

BRASIL. Lei n. 9.433 de 08 de janeiro de 1997. Política Nacional de Recursos Hídricos. Disponível em: https://bit.ly/2qhZy3P. Acesso em: 23 jul. 2020.

BRASIL. Lei n. 12.527, de 18 de novembro de 2011. Lei de Acesso a Informaçóes. Disponível em: http://www.planalto.gov.br/ccivil_03/_ato2011-2014/2011/lei/ 112527.htm. Acesso em: 23 jul. 2020.

CASTRO, A. L. C. et al. Glossário de defesa civil, estudos de riscos e medicina de desastres. Brasília, DF: Ministério da Integração Nacional, 1998.

CCH - COMITÊ DE CRISE HÍDRICA. Plano de contingência para o abastecimento de água da regiáo metropolitana de São Paulo. São Paulo: $\mathrm{CCH}$, 2015. Disponível em: http://www.sigrh.sp.gov.br/public/uploads/news///1318/ planodecontingencia.pdf. Acesso em: 13 jan. 2020.

CUSTÓDIO, V. A crise hídrica na região metropolitana de São Paulo (2014-2015). Geousp - Espaço e Tempo (Online), Sáo Paulo, v. 19, n. 3, p. 445- 
463, 6 dez. 2015. Disponível em: http://www.revistas.usp.br/geousp/article/ view/102136. Acesso em: 21 jul. 2020.

ECONOMIA DE ÁGUA na grande São Paulo fica estagnada em maio. 2015. O Estado de São Paulo, 19 jun. 2015. Disponível em: https://sao-paulo.estadao. com.br/noticias/geral,economia-de-agua-na-grande-sp-fica-estagnada-emmaio, 1709943. Acesso em: 14 jan. 2020.

EDUKATU DISPONIBILIZA novos conteúdos sobre reciclagem e crise hídrica. Braskem, 7 jun. 2016. Disponível em: http://braskem.com.br/detalhe-noticia/ edukatu-disponibiliza-novos-conteudos-sobre-reciclagem-e-crise-hidrica. Acesso em: 14 fev. 2020.

FERRAÇO, A. A. G. A insuficiência de integração na gestão nacional dos recursos hídricos brasileiros como óbice estrutural ao desenvolvimento sustentável. Dissertação (Mestrado) -Universidade de Brasília, Brasília, DF, 2019.

FIGUEIRAS, M. L. Sabesp é generosa com acionistas, mas não com investimentos. Exame, 26 nov. 2014. Disponível em: https://exame.abril.com.br/revista-exame/ nao-da-nem-para-racionar/. Acesso em: 14 jan. 2020.

GIFE - GRUPO DE INSTITUTOS FUNDAÇÓES E EMPRESAS. Instituto Akatu lança campanha "águapedeágua". São Paulo: GIFE, 2015. Disponível em: https:/gife.org.br/instituto-akatu-lanca-campanha-aguapedeagua/. Acesso em: 14 fev. 2020.

IDEC - INSTITUTO BRASILEIRO DE DEFESA DO CONSUMIDOR. Crise hídrica. São Paulo: IDEC, 2014. Disponível em: https://idec.org.br/conquista/ crise-hidrica. Acesso em: 14 fev. 2020.

IDS - INSTITUTO DEMOCRACIA E SUSTENTABILIDADE. Relatório de atividades. São Paulo: IDS, 2014a. Disponível em: https://issuu.com/idsbrasil/ docs/ids_relatorio_2014_simples. Acesso em: 14 fev. 2020.

IDS - INSTITUTO DEMOCRACIA E SUSTENTABILIDADE. Mesa redonda reúne especialistas e imprensa para discutir abordagens e alternativas para a crise hidrica em SP 2014. São Paulo: IDS, 2014b. Disponível em: http://www.idsbrasil. org/multimidia/70/. Acesso em: 14 fev. 2020.

IDS - INSTITUTO DEMOCRACIA E SUSTENTABILIDADE. Segurança hidrica. São Paulo: IDS, 2019. Disponível em: http://www.idsbrasil.org/ iniciativa/2/. Acesso em: 14 fev. 2020.

JACOBI, P. R.; CIBIM, J.; LEĀO, R. S. Crise hídrica na macrometrópole paulista e respostas da sociedade civil. Estudos Avançados, São Paulo, v. 29, n. 84, p. 27-42, ago. 2015. Disponível em: https://www.scielo.br/scielo.php?script=sci_ arttext\&pid=S0103-40142015000200027\&lng=pt\&tlng=pt. Acesso em: 20 jul. 2020 . 
LEITE, I. Governo de São Paulo apresenta plano contra crise hídrica com 5 meses de atraso. G1, 19 nov. 2015. Disponível em: http://g1.globo.com/sao-paulo/ noticia/2015/11/governo-de-sp-apresenta-plano-contra-crise-hidrica-com-5meses-de-atraso.html. Acesso em: 14 fev. 2020.

MACHADO, P. A. L. Direito Ambiental brasileiro. 23. ed. São Paulo: Malheiros. 2013.

MOTTA, L. E. O conceito de Estado e de sociedade civil na perspectiva relacional: conflitos e relaçóes de poder nas arenas públicas. In: III ENCONTRO DE ADMINISTRAÇÃO PÚBLICA E GOVERNANÇA, 3., 2008, Salvador. Anais [...]. Maringá: Anpad, 2008. Disponível em: http://www.anpad.org.br/admin/ pdf/EnAPG89.pdf. Acesso em: 7 jul. 2020.

MPSP - MINISTÉRIO PÚBLICO DO ESTADO DE SÃO PAULO. Crise hídrica açôes e inquéritos. São Paulo: MPSP, 2015. Disponível em: http:// www.mpsp.mp.br/portal/page/portal/comunicacao/Newsletter/imagens newsletter/Crise\%20H\%C3\%ADdrica_a\%C3\%A7\%C3\%B5es\%20e\%20 inqueritos_2015_03_20.xlsx. Acesso em: 14 fev. 2020.

PORTO, G. Não há decisão sobre rodízio exclusivo para o Cantareira diz Alckmin. O Estado de São Paulo, 5 fev. 2015. Disponível em: https://sao-paulo.estadao.com. $\mathrm{br} /$ noticias/geral,nao-ha-decisao-sobre-rodizio-exclusivo-para-o-cantareira-dizalckmin,1630063. Acesso em: 14 fev. 2020.

PRIZIBISCZKI, C. Após 5 anos da crise de abastecimento, SP ainda busca alcançar segurança hídrica. O Eco, 29 set. 2019. Disponível em: https://www. oeco.org.br/reportagens/apos-5-anos-da-crise-de-abastecimento-sp-ainda-buscaalcancar-seguranca-hidrica/. Acesso em: 28 fev. 2020.

REZENDE, F. A crise hídrica na Região Metropolitana de São Paulo em 20132015: origens, impactos e soluçóes. In: BUCKERIDGE, M.; RIBEIRO, M. C. (coords.). Livro branco da água. Sáo Paulo: Instituto de Estudos Avançados da Universidade de São Paulo, 2018. Disponível em: http://www.iea.usp.br/ publicacoes/ebooks/livro-branco-da-agua/view. Acesso em: 21 jul. 2020. [E-book].

RIBEIRO, L. C. Q. Desastres urbanos: que lição tirar? Observatório das Metrópoles, 30 jan. 2011. Disponível em: observatoriodasmetropoles.net.br/desastresurbanos-que-licao-tirar. Acesso em: 14 fev. 2020.

SABESP AMPLIA faixa de bônus para quem economizar água em São Paulo. G1, 21 out. 2014. Disponível em: http://g1.globo.com/sao-paulo/noticia/2014/10/ sabesp-amplia-faixa-de-bonus-para-quem-economizar-agua-em-sp.html. Acesso em: 14 jan. 2020.

SÃO PAULO. Lei n. 7.663, de 30 de dezembro de 1991. a Política Estadual de 
Recursos Hídricos de São Paulo (PERH-SP). Disponível em: https://www.al.sp. gov.br/repositorio/legislacao/lei/1991/lei-7663-30.12.1991.html>. Acesso em: 23 jul. 2020.

SILVA, J. L.; SAMORA, P. R. Os impactos da crise hídrica sobre a população do município de Campinas/SP (2012-2016). Urbe. Rev. Bras. Gest. Urbana, Curitiba, v. 11, 2019. Disponível em: http://www.scielo.br/scielo.php?script=sci arttext\&pid=S2175-33692019000100242\&lng=en\&nrm=iso. Acesso em: 21 jul. 2020.

SORIANO, E. et al. Crise hídrica em São Paulo sob o ponto de vista dos desastres. Ambiente \& Sociedade, São Paulo, v. XIX, n. 1, p. 21-42, 2016. Disponível em: http://www.scielo.br/pdf/asoc/v19n1/pt_1809-4422-asoc-19-01-00021.pdf. Acesso em: 14 fev. 2020.

UNISDR - UNITED NATIONS INTERNATIONAL STRATEGY FOR DISASTER REDUCTION (UNISDR). Recovery. UN/ISDR - UN Office for DRR. 2009. Disponível em: http://preventionweb.net/go/499. Acesso em: 14 fev. 2020.

WISNER, B. et al. At Risk: natural hazards, people`s vulnerability and disasters. London: Routledge, 2003.

ZOROWICH, A. C. Cisternas Já. São Paulo: Ecoeficientes - Escritório de arquitetura especializado em sustentabilidade, 2014. Disponível em: http://www. ecoeficientes.com.br/movimento-cisterna-ja/. Acesso em: 14 fev. 2020. 